\title{
Comparison of Supraclavicular Artery Flap and Skin Graft in Management of Neck Contractures
}

\author{
ZAHID IQBAL BHATTI ${ }^{1}$, MUHAMMAD IMRAN ${ }^{2}$, MUHAMMAD NADEEM ${ }^{3}$, SARFRAZ AHMAD ${ }^{4}$, TAUQEER NAZIM ${ }^{5}$ \\ ${ }^{1}$ Assistant Professor of Plastic Surgery, Nawaz Sharif Medical College Gujrat \\ ${ }^{5}$ Senior Registrar, Plastic Surgery, Lahore General Hospital, Lahore \\ ${ }^{3}$ Associate Professor of ENT, M. Islam Medical \& Dental College, Gujranwala \\ ${ }^{4}$ Assistant of Professor of Plastic Surgery, Khawaja Muhammad Safdar Medical College/Allama lqbal Teaching Hospital, Sialkot \\ ${ }^{5}$ Assistant Professor of Plastic Surgery, Shaikh Zayed Hospital, Lahore \\ Correspondence to Dr. Sarfraz Ahmad, E-mail: doctorfazi@gmail.com Cell: 0333-4386526
}

\begin{abstract}
Background: Burn cases are highly prevalent in developing countries like Pakistan. If not managed timely they can result in lifetime complications as well as morbidity.

Aim: To compare the supraclavicular artery flap method with skin graft.

Place and duration of study: Department of Plastic Surgery, Allama Iqbal Memorial Hospital, Sialkot from $1^{\text {st }}$ September 2015 to $31^{\text {st }}$ August 2019.

Methodology: In this comparative study forty four patients were enrolled and half were operated by supraclavicular artery flap method and other half by skin graft procedure. The patients were followed for their skin contour, colour matching and neck extension improvement and recurrent neck contracture after a year.

Results: Mean age of the patients was 29.5 years with $75 \%$ as females. Only one patient had recurrent neck contracture from supraclavicular artery flap group while $81.8 \%$ of skin graft showed recurrent neck contracture

Conclusion: Supraclavicular artery flap is a better management approach in post neck contracture burn patients. Key words: Supravlaciular artery flap, Skin graft, Neck contractures
\end{abstract}

\section{INTRODUCTION}

Neck contractures can cause severe aesthetic impairment and dysfunction. It can severely result in mastication, breathing disorders, phonic issues and also neck aches. Detailed surgery for treatment of neck contractures caused by burns can be a positive approach for providing a better chance of life to the patients. ${ }^{1}$ The prevalence of neck contractures is highly reported in countries where burn incident ratio is much higher due to accidents other than road side burns or house burns. Acid attacks, victimization is more common in developing countries causing higher number of patient ratio being affected by neck contractures. ${ }^{2}$ Another unfortunate event is that in South east Asian countries as Pakistan the burn management care is still not upto mark resulting in post burn contractures. ${ }^{3}$ Long time bandaging and soft neck skin are also added factors leading to post neck contractures ${ }^{4}$. Women and children are most affected population for neck contractures. In growing children neck contractures causes pulling/stretching of chin and cervical downward due to neck contracture resulting in permanent disability for lifetime ${ }^{5}$.

The two surgical approaches for treating neck contracture could be either supraclavicular artery flap or skin graft. Each of the surgical procedure has its own pros and cons $^{6-7}$. The present study was designed to compare the supraclavicular artery flap with skin graft in managing the neck contractures. The goal of this study was to analyzed the outcome in consideration of improved extension/movement of neck, esthetics and rate reduction of contraction formation after a year as follow up.

Received on 19-04-2021

Accepted on 22-08-2021

\section{PATIENTS AND METHODS}

It was a hospital based comparative study conducted at Department of Plastic Surgery, Allama lqbal Memorial Hospital, Sialkot from $1^{\text {st }}$ September 2015 to $31^{\text {st }}$ August 2019 after approval from IRB and comprised 44 patients. Both genders, age between 10-50 years and post-burn neck contracture were included. Patients were than divided into two groups. Twenty two patients with neck contracture were operated with supraclavicular artery flap method whereas other 22 patients went under skin graft surgical procedure. Those patients which were either operated previously from other hospitals for post neck contractures or had an infection, sinus or fistula formation over neck were excluded from the study. An informed consent was gained from each participant. Their sociodemographic as well as clinical assessment data were noted. A local examination of each patient was performed keeping classification guidelines of Achauer and Salisbury/Bevin under consideration ${ }^{8,9}$. The clinical examination included skin texture, skin color match, and contouring. Assessment of atlanto occipital-extension was conducted by asking patient to sit in a straight posture with erected head and facing front. ${ }^{10}$ "Neck deficit grading system" was applied for grading of post neck contractures. Grade 1: normal extension level as >110 degrees, Grade 2: extension horizontal level (95 to 110 degrees), Grade 3: Neck extension only upto horizontal level as 85-95 degrees and Grade 4: below horizontal plane less than 85 degrees. The surgical procedure for flap included preparation and dressing of neck and shoulder. Triangle site was marked showing flap-pedicle. It was restricted medially by sternocleidomastoid at posterior border, posteriorly through external-jugular vein and also with clavicle inferiorly. A marking of flap was then done on patient's shoulder post 
received of template of defect formulated from post burn NC release. Incision of subcutaneous tissue, fascia after skin at deltoid muscle was performed as well as flap lifting sub fascial plane was also conducted at distal proximal route. Dissection was performed until supraclavicular artery was seen under omohyoid muscle (posterior-belly). In middle third of flap: transillumination method was used to identify and confirmed supraclavicular artery. It was made assure that spinal accessory nerve was kept preserved. The inferior part of skin was jointed with the deformity whereas undamaged proximal part was left over flap pedicle. Through a 180-degree rotation the lifted flap was then brought over the defect. The dimensions of collected SC-A flap were from $28 \times 10 \mathrm{~cm}^{2}$.

The operative protocol applied to skin graft patients included lying flat on operation theatre table and grafting of skin which was $n$ harvested from thigh area for treating of their neck contractures. Only neck collar which was custom made was prescribed to all the patients in day time for at least three months duration. The stitches on their grafted skin area were removed on day $10^{\text {th }}$. Each patient was followed up for their skin or flap status and neck movement until three months. The frequency of recurrent neck contracture was only at one year post-operatively.

The data was analyzed by using SPSS version 23.0. The Chi square test was applied and $p$ value $<0.05$ was considered significant.

\section{RESULTS}

Thirty three (75\%) were females and 11 (25\%) were males with mean age was $29.5 \pm 2.5 y e a r s$ (Table 1). Most of the neck contracture caused by grade 3 burns (54.5\%) in 24 patients followed by 14 patients having grade 2 burns $(31.8 \%)$. Grade 4 burns were only seen in 6 patients $(13.6 \%)$ out of which four $(9.09 \%)$ were females (Table 2$)$.

Patients satisfaction of their graft after six months follow-up was 18 (81.8\%) in SC-A flap group and 5 (22.7\%) in skin grafting group (Table 3). The partial loss of skin graft was seen in $31.8 \%$ patients $(n=14)$ out of 22 patients of skin grafting while delayed healing was noticed in $13.6 \%$ such as only in 6 patients. Within these 6 patients four were skin grafted and only 2 of SC-A flap cases had delayed healing (Table 4).

Eighteen patients (81.8\%) with skin graft had recurrent neck contracture at a year follow-up with only one $(4.5 \%)$ with SC-A flap case reported (Fig. 1).

Table 1: Distribution of gender according to age in both groups

\begin{tabular}{|l|c|c|c|c|}
\hline \multirow{2}{*}{ Age (years) } & \multicolumn{2}{|c|}{ SCA flap } & \multicolumn{2}{c|}{ Skin graft } \\
\cline { 2 - 5 } & Male & Female & Male & Female \\
\hline $10-20$ & 1 & 1 & - & 1 \\
\hline $21-30$ & 3 & 8 & 2 & 11 \\
\hline $31-40$ & 2 & 3 & 1 & 4 \\
\hline $41-50$ & 1 & 2 & 1 & 3 \\
\hline Total & 7 & 14 & 4 & 19 \\
\hline$p>0.05$
\end{tabular}

$p>0.05$

Table 2: Distribution of gender according to groups in terms of burn grading

\begin{tabular}{|l|c|c|c|c|}
\hline \multirow{2}{*}{ Grade } & \multicolumn{2}{|c|}{ SCA flap } & \multicolumn{2}{c|}{ Skin graft } \\
\cline { 2 - 5 } & Male & Female & Male & Female \\
\hline II & $1(20 \%)$ & $6(35.3 \%)$ & $3(50 \%)$ & $4(25 \%)$ \\
\hline III & $3(60 \%)$ & $9(19.1 \%)$ & $2(33 \%)$ & $10(62.5 \%)$ \\
\hline IV & $1(20 \%)$ & $2(11.7 \%)$ & $1(17 \%)$ & $2(12.5 \%)$ \\
\hline Total & $5(11.3 \%)$ & $17(38.6 \%)$ & $6(13.6 \%)$ & $16(36.3 \%)$ \\
\hline
\end{tabular}

Table 3: Comparison of patient's satisfaction in both groups $(n=23)$
\begin{tabular}{|l|c|c|c|c|}
\hline \multirow{2}{*}{ Grade } & \multicolumn{2}{|c|}{ SCA flap } & \multicolumn{2}{c|}{ Skin graft } \\
\cline { 2 - 5 } & Male & Female & Male & Female \\
\hline II & 1 & 6 & 1 & 3 \\
\hline III & 2 & 7 & - & 1 \\
\hline IV & 1 & 1 & - & - \\
\hline Total & 4 & 14 & 1 & 4 \\
\hline
\end{tabular}

$\mathrm{P}<0.05$

Table 4: Distribution of graft loss and delayed healing in SC-A flap procedure with skin graft

\begin{tabular}{|l|c|c|}
\hline Variable & SCA flap & Skin graft \\
\hline Skin graft loss & -- & 14 \\
\hline Delayed partial loss & 2 & 4 \\
\hline Healthy outcomes & 20 & 4 \\
\hline Total & 22 & 22 \\
\hline
\end{tabular}

Fig 1: Comparison of recurrent according to supraclavicular artery flap with skin graft

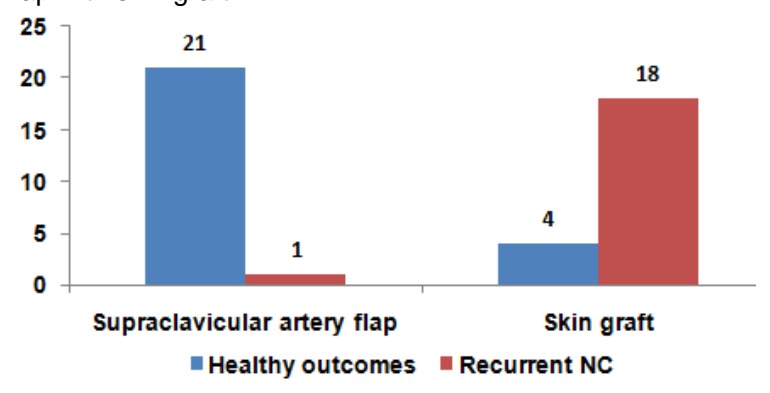

\section{DISCUSSION}

In present study $54.5 \%$ of the patients were between $21-30$ years of age group. A study in similar context reported $45 \%$ of their enrolled burn patients to be between 21-30 year of age $^{6}$. The mean age reported was $29.5 \pm 2.5$ years. Mody et $\mathrm{al}^{6}$ also reported similar age group to be mostly affected by NC. The mean age in various studies lies between 21.2 years to 28.3 years which is also similar to current study ${ }^{11,12,13}$.

Various studies reported $64 \%$ to $77.3 \%$ female affected by NC burns which is similar to present study estimated prevalence of females. The justification behind this is more domestic violence in developing countries and poor fire management protocols used in house hold ${ }^{13-18}$.

The dimension of flap used in the present study were in accordance to already reported as exact and near to the values provided in other research data. ${ }^{2,19}$ Further the present study reported only a single case of recurrent NC in SC-A flap group with only two patients who had delayed healing in SC-A flap group. Whereas skin graft operative procedure showed majority of recurrent NC cases and graft loss/delayed healing. Similar findings has been reported by other researchers which emphasized on SC-A flap operative procedure to be more reliable for NC than skin grafting approach ${ }^{20-24}$.

\section{CONCLUSION}

Supraclavicular artery flap surgery procedure is much effective and reliable than skin graft approach in neck contracture though after burns.

Conflict of interest: Nil 


\section{REFERENCES}

1. Akita S, Hayashida K, Takaki S, Kawakami Y, Oyama T, Ohjimi $\mathrm{H}$. The neck burn scar contracture: a concept of effective treatment. Burn Trauma 2017; 5: 22

2. Saaiq M. Supraclavicular artery flap versus skin graft: which is a better reconstructive tool for managing post-burn contractures in the neck. World J Plast Surg 2021;10(1):1521.

3. Saaiq M, Ashraf B. Epidemiology and outcome of self-inflicted burns at Pakistan Institute of Medical Sciences, Islamabad. World J Plast Surg 2014; 3(2):107-14

4. Saaiq M, Zaib S, Ahmad S. The menace of post-burn contractures: a developing country's perspective. Ann Burns Fire Disasters 2012;25:152-8.

5. Grishkevich VM, Grishkevich M, Menzul V. Postburn neck anterior contracture treatment in children with scar-fascial local trapezoid flaps: a new approach. J Burn Care Res 2015;36:e112-9.

6. Mody NB, Bankar SS, Patil A. Post burn contracture neck: clinical profile and management. J Clin Diagn Res 2014; 8(10):NC12-7.

7. Devi SR, Kalita H, Baishya J, Boruah P. Functional and esthetic considerations in reconstruction of post-burn contracture of the neck. Indian J Burns 2013;21:58.

8. BM Achauer. Neck reconstruction. In: Achauer BM, ed. Burn Reconstruction. New York: Thieme Medical Publishers, 1991; 79-86.

9. Salisbury RE, Bevin AG. Atlas of reconstructive burn surgery. Philadelphia: WB Saunders, 1981; 89-105.

10. Benumof JL. Management of the difficult adult airway. Anesthesiology 1991;75: 1087.

11. Angrigiani C. Aesthetic microsurgical reconstruction of anterior neck burn deformities. Plast. Recostr Surg 1993;93:507.

12. Kadir MSA. Post burn flexion neck contracture. Tikrit Med $J$ 2007; 13(1):116-21.
13. Bhattacharya S, Bhatnagar SK, Chandra R. Post-burn contracture of the neck - our experience with a new dynamic extension splint. Burns 1991; 17:65.

14. Loghmani S, Eidy $M$, Mohammadzadeh $M$, Loghmani A, Raigan $F$. The supraclavicular flap for reconstruction of postburn mentosternal contractures. Iran Red Crescent Med J2013;15:292-7.

15. Ismail H, Elshobaky A. Supraclavicular artery perforator flap in management of post-burn neck reconstruction: clinical experience. Ann Burns Fire Disasters 2016; 29:209-14.

16. Moustafa MF, Borhan A, Abdel Fattah AMF. Burn contractures of the neck. Plast Reconstr Surg 1978;62:6.

17. Maneksha RJ. Transactions of the IX International Congress of Plastic and Reconstructive Surgery; New Delhi, India March 1-6, 1987. New Delhi: Tata McGraw-Hill Publishers, 1987.

18. Ahuja RB, Bhattacharya $\mathrm{S}$. The etiology and treatment of intrinsic discolorations. BMJ 2004; 329(7463): 447-9.

19. Telang $P$, Jagannathan $M$, Devale $M$. A study of the use of the supraclavicular artery flap for resurfacing of head, neck, and upper torso defects. Indian J Plast Surg 2009;42:4-12.

20. Vinh VQ, Van Anh T, Ogawa R, Hyakusoku H. Anatomical and clinical studies of the supraclavicular flap: analysis of 103 flaps used to reconstruct neck scar contractures. Plast Reconstr Surg 2009;123:1471-80.

21. Ross RJ, Baillieu CE, Shayan R, Leung M, Ashton MW. The anatomical basis for improving the reliability of the supraclavicular flap. J Plast Reconstr Aesthet Surg 2014;67:198-204.

22. Herr MW, Emerick KS, Deschler DG. The supraclavicular artery flap for head and neck reconstruction. JAMA Facial Plast Surg 2014;16:127-32.

23. Telang $P$, Jagannathan $M$, Devale $M$. A study of the use of the supraclavicular artery flap for resurfacing of head, neck, and upper torso defects. Indian J Plast Surg 2009;42:4-12.

24. Sheriff H, Garcia CV, Jaber S, Ojea DB, Kareem SS, Garrido MF, Masia J. Supraclavicular artery island flap: relation between length and distal end necrosis. IMJ 2018; 2:5. 